\title{
Unusual presentations of Glioblastoma Posterior Fossa and spinal cord: Cases Presentations and Review of Literature
}

\author{
Lucia Richter Paz ${ }^{1,2}$, Pedro Vega Tadic ${ }^{4}$, Gabriela Antelo ${ }^{3}$, Eduardo Velasco ${ }^{3}$ and Ronald Limon Tellez ${ }^{2,3,5}$ \\ ${ }^{1}$ Centro mèdico Aliviar Santa Cruz, Bolivia \\ ${ }^{2}$ Centro de mastologia y oncologia CMO Santa Cruz, Bolivia \\ ${ }^{3}$ Instituto Oncològico del Oriente Boliviano Santa Cruz, Bolivia \\ ${ }^{4}$ Oncos laboratorio de patologia y biologia molecular Santa Cruz, Bolivia \\ ${ }^{5}$ Centro investigaciòn Universidad Mayor Real y Pontificia de San Francisco Xavier de Chuquisaca Sucre - Bolivia
}

Submission: February 26, 2020; Published: March 06, 2020

"Correspondence Author: Ronald Limon Tellez, Centro de mastologia y oncologia CMO Santa Cruz, Instituto Oncològico del Oriente Boliviano, Centro investigaciòn Universidad Mayor Real y Pontificia de San Francisco Xavier de Chuquisaca Sucre, Bolivia

\begin{abstract}
In general, Glioblastomas multiforme frequently occurs in supratentorial region but in less than $4 \%$ occur in the posterior fossa predominantly in the cerebellum, and spinal cords tumors represents $6 \%$ to $8 \%$ of all central nervous system tumors and spinal cord glioblastomas occur only in $1.5 \%$ of all spinal cords tumors. We presents two cases a male whit posterior fossa glioblastoma and a girl with spinal cord glioblastoma in both cases, MRI is the study of choice with high sensitivity and specificity for diagnosis, after that they underwent biopsy and the results of pathology described GBM in both cases. The treatment of election is radiotherapy plus chemotherapy and surge if is possible, the prognosis is poor even with treatment, thats is why we need to identify new therapeutic strategies; We currently believe it is necessary to use genetic platforms to identify possible therapeutic targets.
\end{abstract}

\section{Introduction}

Glioblastoma (GBM) is the most frequent tumor of the central nervous system representing $50 \%-60 \%$ of all brain tumors [1], they occur most frequently from 50 - 70 years and their most frequent location is supratentorial; posterior fossa glioblastomas are very rare and represent a challenge for diagnosis since they are confused with metastatic lesions [2], this location correspond to $0.24 \%$ to $1 \%$ of the total glioblastomas; followed by intramedullary tumors that represent approximately $3 \%$ of all neoplasms [3], $1 \%$ corresponds to primary spinal cord glioblastoma and 3 to $5 \%$ of these tumors can be high grade neoplasms [4]. Intramedullary glioblastomas are characterized by blocking the basal cisterns, increase cerebrospinal fluid protein producing hydrocephalus, its clinical presentation includes sensory and motor deficits; Literature and information is very limited $[5,6]$. GBMs located in the posterior fossa can cause various cerebellar symptoms such as headache, gait disorders, ataxia, nausea and vomiting. These findings may suggest the existence of a massive lesion in the posterior fossa. Surgery in both presentations remains the treatment of choice if possible; followed by adjuvant treatment with Temozolomide (TMZ), -Radiotherapy in the case of a recurrence palliation remains the alternative of choice including biological therapy $[7,8]$. The presentation of glioblastoma in cerebellum and intramedullary is extremely rare, and few reports of clinical cases with these characteristics have been published. Its etiology and prognosis are poorly clarified due to lack of data in the literature. We present two clinical cases of glioblastoma with location in the posterior fossa and another intramedullary, being the first report in our country.

Case 1

Male patient, 29 years old born in Santa Cruz, Bolivia. Patient was diagnosed with a medulloblastoma in 2012 located in the posterior fossa (Figure 1). August 2012 control MRI at posterior fossa and on the right cerebellar hemisphere, a heterogeneous, 


\section{Cancer Therapy \& Oncology International Journal}

isodense image is observed with some hyper-intense sectors in T2 and hypointense in T1 and Flair, extends to vermis,

mass effect by displacing the medulla and annular protuberance. compresses and displaces the IV ventricle to the left causing

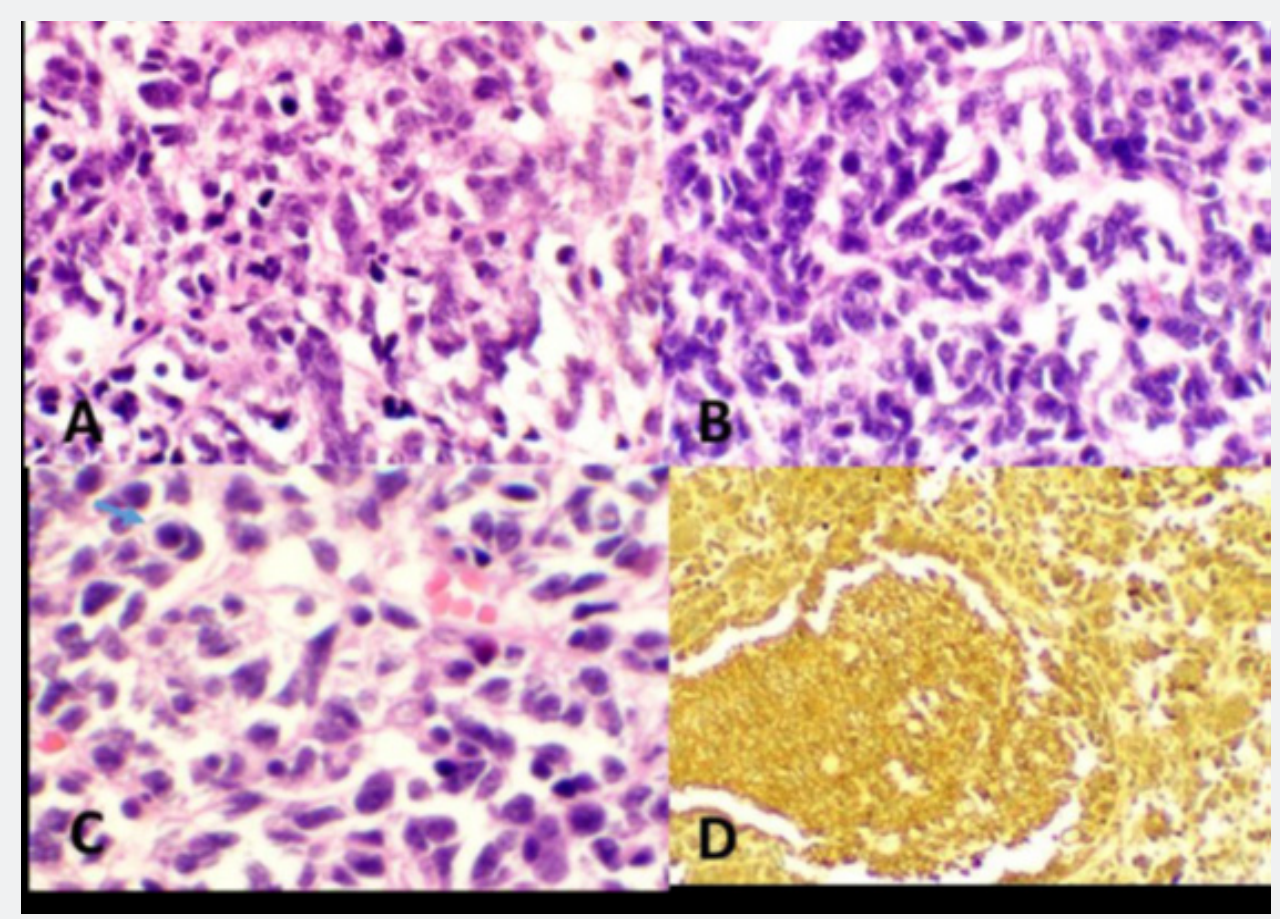

Figure 1: Large Cell / Anaplastic Medulloblastoma. A, B Hypercellular tumor with increased tumor cell size, nuclear pleomorphism, nuclear molding, and C "cell wrapping" (arrow). D Immunohistochemistry shows diffuse and intense positive staining of tumor cells against synaptophysin. It was negative against GFAP (Glial Acidic Fibrillar Protein) not shown.

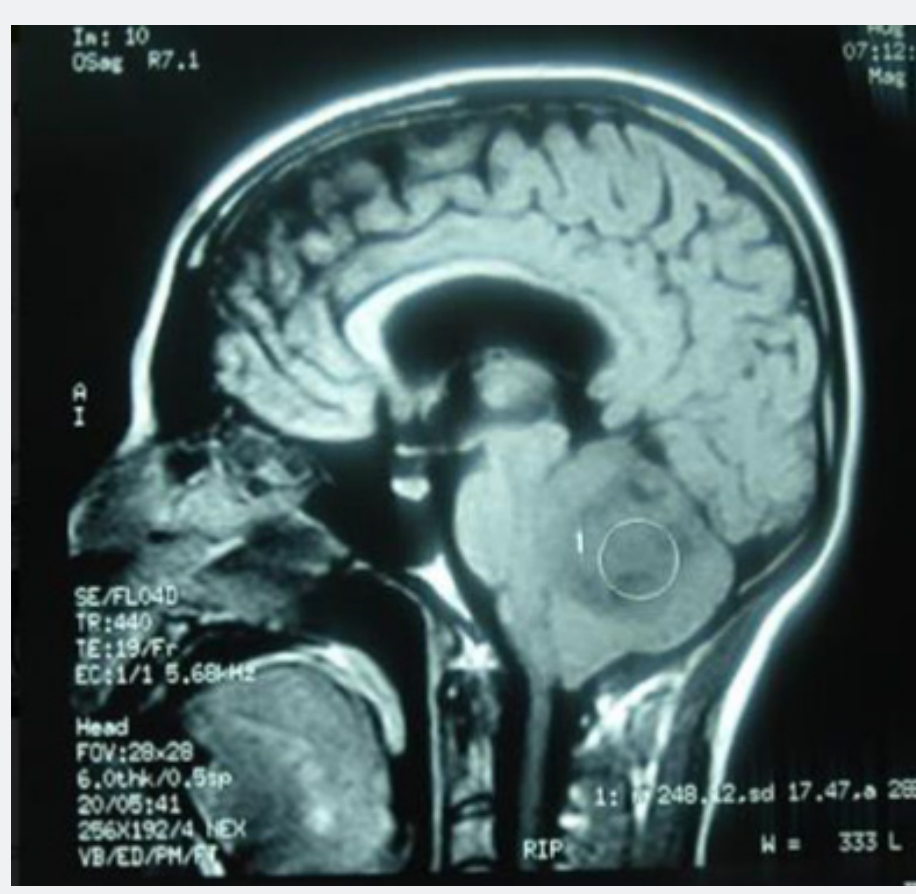

Images1 


\section{Cancer Therapy \& Oncology International Journal}

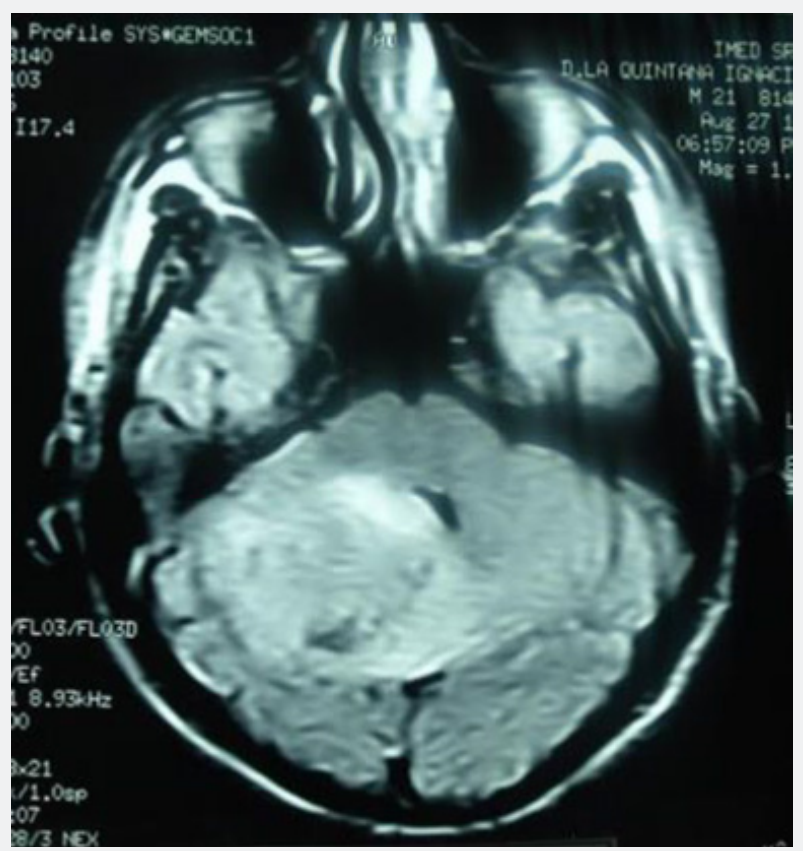

Images2

Complete resection (R0) is performed followed by $54 \mathrm{~Gy}+$ 36Gy holocranean radiotherapy to the spine (neuroaxis). Good postoperative evolution. It remains in clinical controls until 2013 and does not return to oncologist. In July of 2019 presents severe headache and cerebellar syndrome, Brain CT shows right occipital craniectomy, Left cerebellar hemisphere, brain stem, basal ganglia, thalamus and brain hemispheres of morphology and normal density.
In August of 2019 new MRI of the skull described heterogeneous lesion at the cerebellum level measures $3.2 \mathrm{~cm}$ with multiple satellite nodules, heterogeneous reinforcement of anfractuous edges that determines a decrease in the floor of the third ventricle, an increase in the amplitude of the supratentorial ventricular system with periventricular leukoaraiosis conditioning amplitude of the IV ventricle. Right suboccipital craniectomy (Image 3).

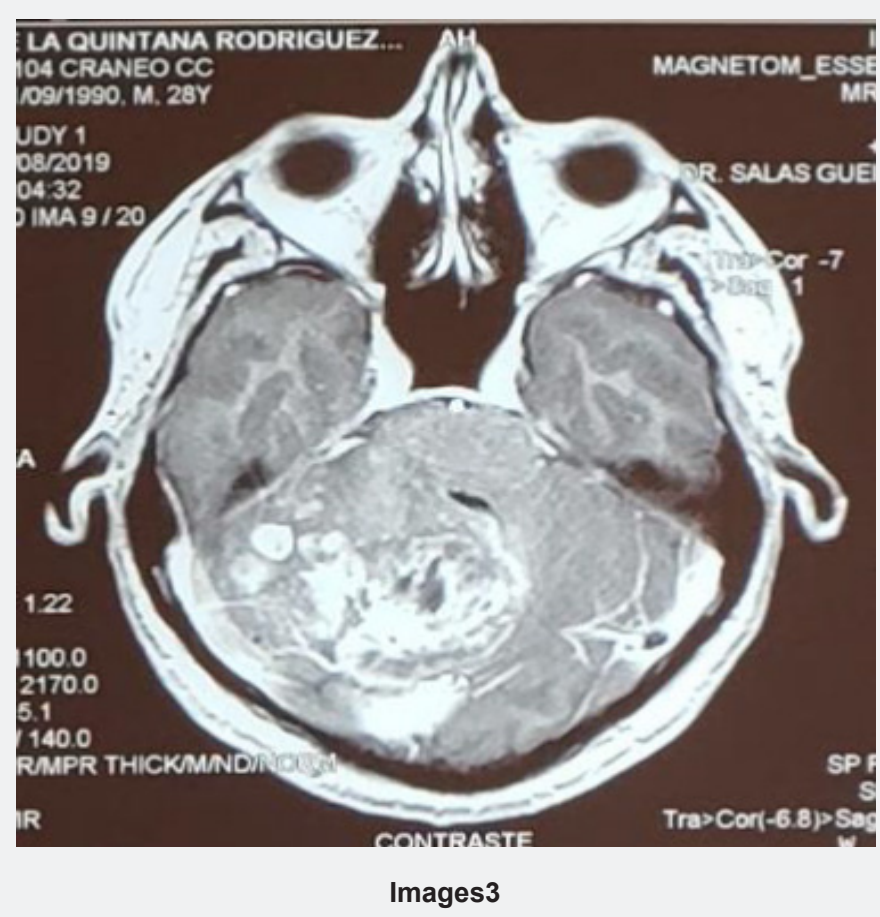




\section{Cancer Therapy \& Oncology International Journal}

Emergency admission due to severe headache, vomiting, poor general condition, impaired consciousness. Cerebellar syndrome. Assessed by neurosurgery, craniotomy with biopsy taking is defined given the unrespectability of the lesion. The result of pathological anatomy informs GLIOBLASTOMA NOS.

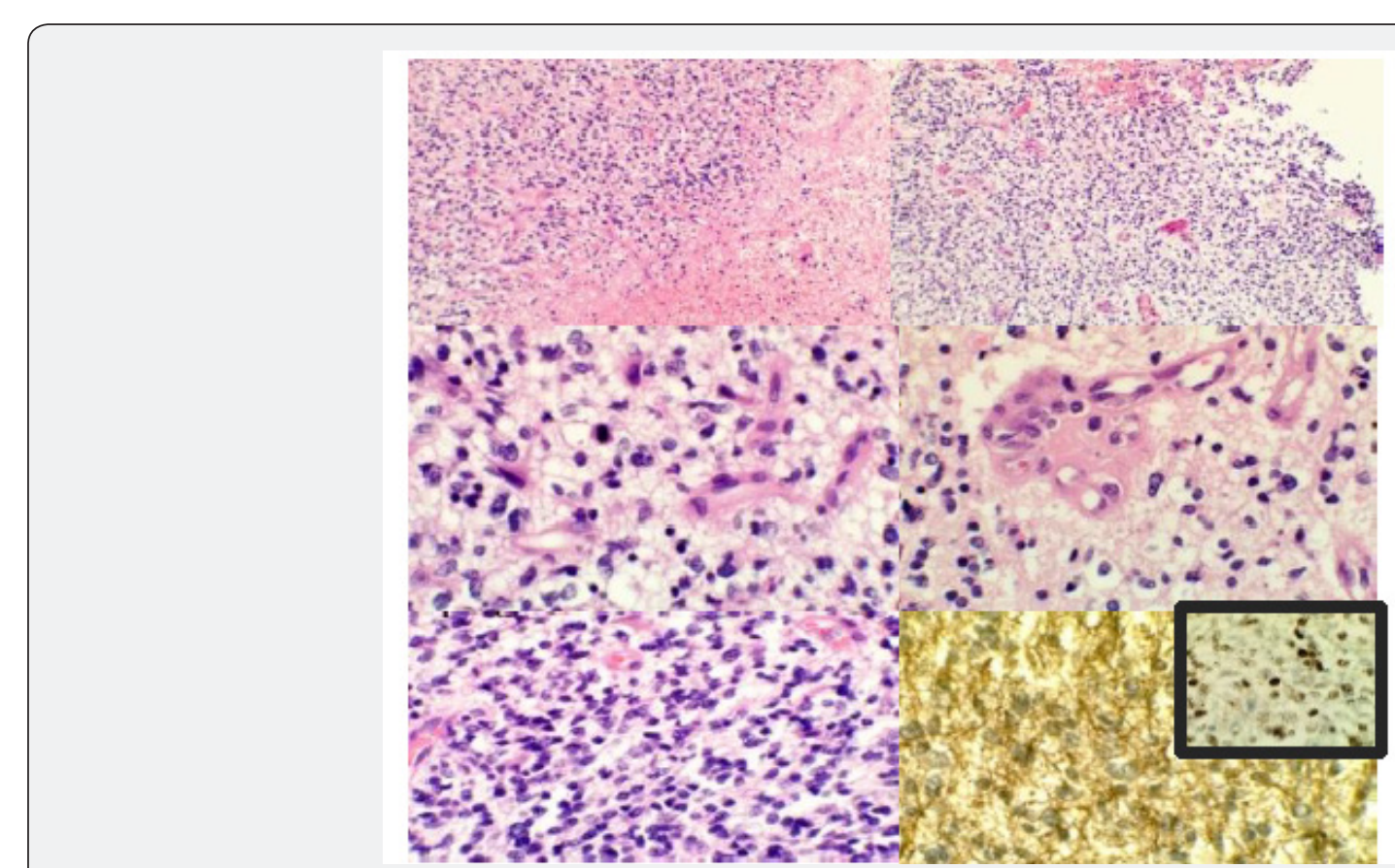

Figure 2: Glioblastoma NOS. A, B Hypercellular glial tumor, with extensive focus of ischemic necrosis surrounded by palisade-like tumor cells, predominantly microvascular proliferation surrounding necrosis. C pleomorphic tumor cells in fibrillar stroma, with mitotic figures. D Microvascular proliferation. E Foci of medium to small monomorphic tumor cells. F Immunohistochemistry shows diffuse and intense positive staining of tumor cells against GFAP (Glial Acid Fibrillary Protein) and Ki67 shows high proliferation index (upper right box) Synaptophysin was negative (not shown).

Note: Tumor cells are diffuse immunoreactive with GFAP (Glial acidic fibrillar protein), approximately $50 \%$ positive against Ki67 and are negative against synaptophysin (Figure 2).

Previous biopsy is reviewed and diagnosis of medulloblastoma emitted at that time is confirmed, so the current tumor can be considered as radiation-induced GLIOBLASTOMA at the treated site. September 2019: placement of peritoneal ventricular bypass due to hydrocephalus. Valued by the Radiotherapy Service, re irradiation is ruled out for having received a maximum dose in 2012. In touch with the Clinical Oncology and Palliative Care team on 10/15/19, poor general condition, ECOG PS 4, sleepy, disoriented. Febrile. Pneumonia due to Broncho aspiration. Symptomatologic therapeutic measures are initiated.

Discussed in the Tumor Committee, a molecular platform request is defined, given the rarity of the presentation. Starts Temozolomide $200 \mathrm{mg} / \mathrm{m}^{2}$ D1 - D5 by nasogastric tube. Patient is evaluated by the Palliative Care team, followed by cerebral edema, persistent hiccups and recurrent or aspiration pneumonia. Initially SNG is placed. He is discharged at home with symptomatic treatment phenytoin $100 \mathrm{mg}$ c / 12, prednisone $20 \mathrm{mg} \mathrm{c} / 4 \mathrm{hrs}$, ondasetron $8 \mathrm{mg} \mathrm{c} / 8 \mathrm{hrs}$, tramadol 100mg c / $8 \mathrm{hrs}$, metoclopramide $10 \mathrm{mg}$ C78hrs, lactulose $10 \mathrm{ml} \mathrm{c} / 8 \mathrm{hrs}$. and follow-up at home together with family and through telephone contact. Once the final stage of the disease is confirmed, it changes to the subcutaneous route and NGS is removed. Patient dies at home surrounded by his family.

\section{Case 2}

A 13-year-old woman with no relevant pathologic history, presented in December 2018 cervical pain, nausea, vomiting and fever, 4 days after admission presented left hemiparesis and right hemiplegia. Magnetic resonance cervical spine described: intramedullary neoformative lesion that extends from C2 - C7 (Image 4).

In April 2019 she underwent laminotomy and laminoplasty in C5 and biopsy. Histopathological findings report neoplastic proliferation of glial aspect constituted by ovoid or fusiform nucleus cells with variable eosinophilic cytoplasm with short or elongated processes, microvascular hyperplasia, necrosis in palisade and areas of greater density are observed cell with pleomorphism and mitosis. Immunohistochemistry: Histone 3M (-) neoplastic cells; Histone k27M (+) neoplastic cells; Olig2 (+) nuclear; p53 not evaluable and Ki 67: 60-70\%. Sequencing reaction: Amplification of the segment of the H3F3A gene detected; K27M mutation detected (Figure 3). 


\section{Cancer Therapy \& Oncology International Journal}

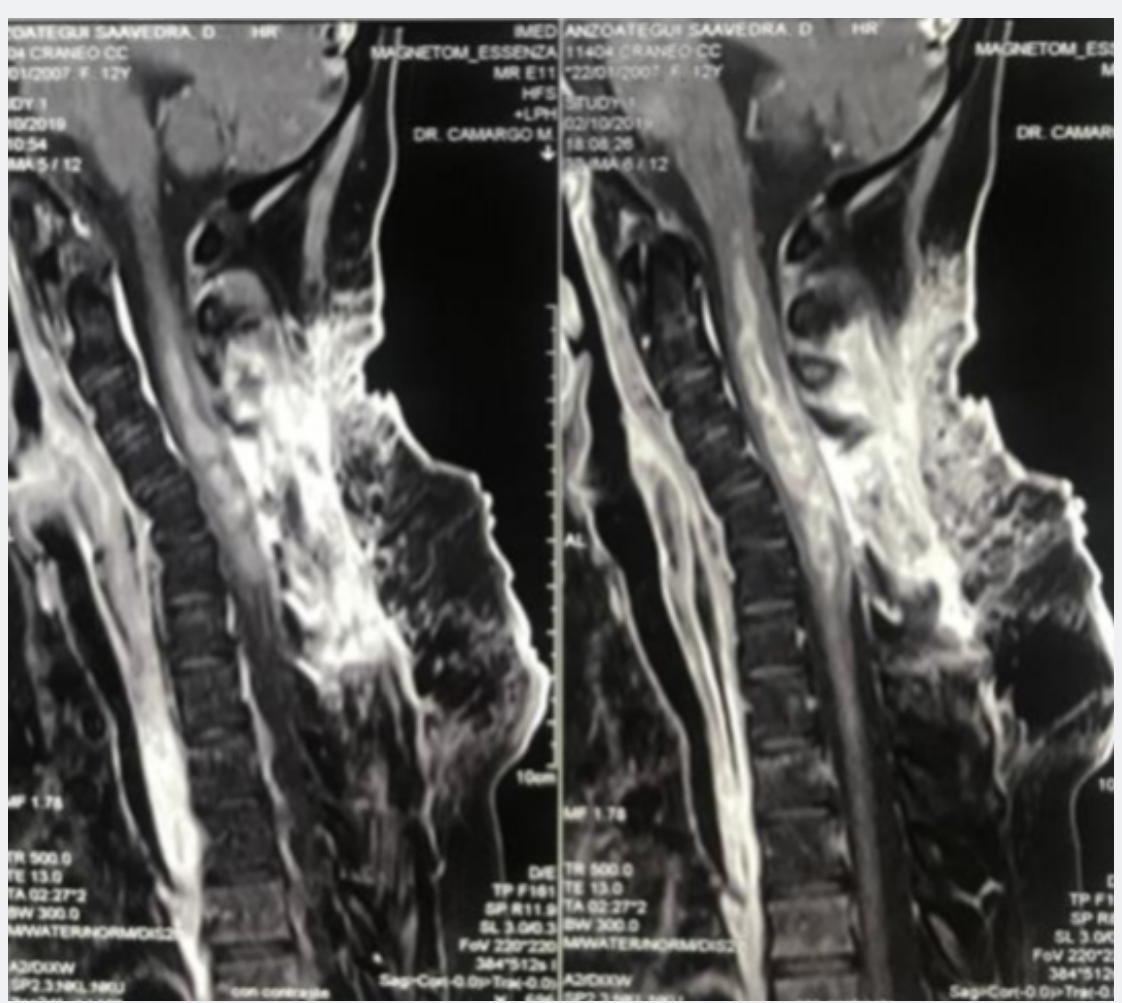

Images 4

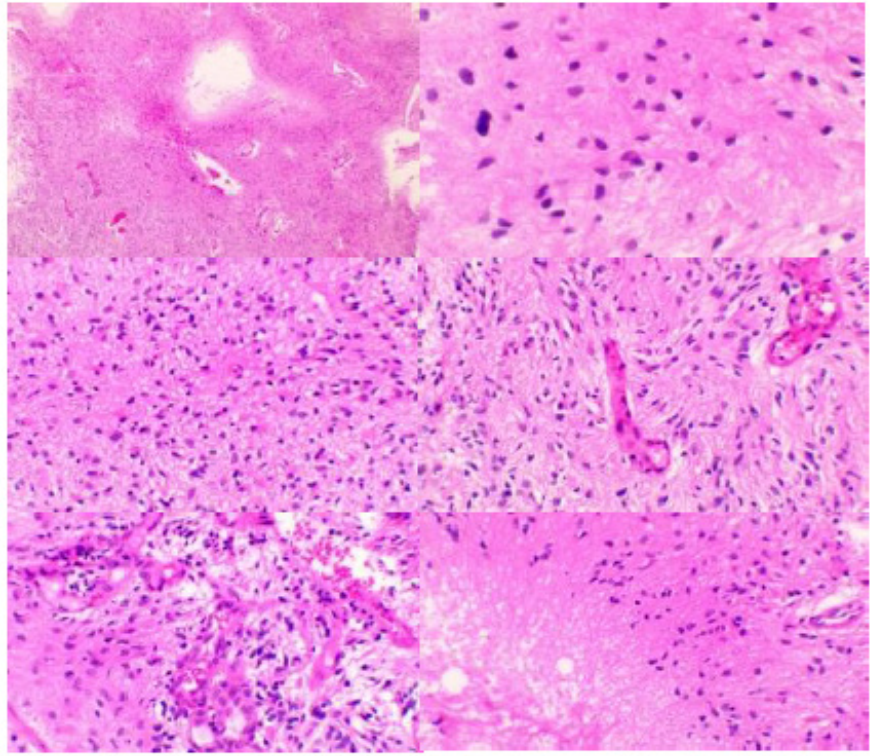

Figure 3: Glioblastoma. Glial neoplastic proliferation consisting of ovoid or fusiform nucleus cells with variable eosinophilic cytoplasm with short or elongated processes, some eccentric nucleus cells and abundant homogeneous eosinophilic cytoplasm (A, B). They are diffusely arranged on fibrillar stroma $(C)$, with a focal tendency for perivascular disposition without constituting pseudo-soils (D). Microvascular hyperplasia $(E)$ and palisade necrosis $(F)$ are observed.

After surgery began treatment with bulbo-medullary radiotherapy until completing 54 Gy associated with Temozolomide orally $75 \mathrm{mg} / \mathrm{m}^{2} /$ day culminating in June
2019; after that she presented febrile neutropenia radiological studies shows pneumonia due to atypical germs, he received antibiotic treatment of broad spectrum requiring intensive care 


\section{Cancer Therapy \& Oncology International Journal}

in the unit care for respiratory failure and she was discharged in July 2019 due to this she had interruption of cancer treatment; new MRI study described: expansive formation with respect holomedular a thin peripheral band extending from the bulbmedullary junction to collapse level D1 with the peri medullary subarachnoid space all in relation to disease progression and she started second line of treatment with Bevacizumab / Temozolomide (TMZ). Control MRI shows partial response, at the time of the report patient continues with its treatment.

\section{Discussion}

High-grade gliomas are malignant brain tumors, often rapidly progressive, divided into anaplastic gliomas (anaplastic astrocytoma, anaplastic oligodendroglioma) and glioblastoma based on their histopathological and molecular characteristics [9].

Primary CNS tumors are found in $20 \%$ in childhood, being the second cause of death after leukaemia, of which $70 \%$ are located in the cerebellum, brainstem (posterior fossa, infratentorial), differentiating them from adults in whom most tumors originate in the supratentorial region, occur in people older than 45 years. The incidence of gliomas decreases with age, except for glioblastoma that generally occurs after 45 and increases, representing more than $50 \%$ of gliomas [9]. Draws attention the age of presentation of case 1 , which is rare age of presentation of this type of tumors.

From the 2016 edition of the WHO, gliomas are classified according to not only the histopathological appearance but also well-established molecular parameters [10], these characteristics have changed the classification of astrocytic and oligodendroglial tumors, which are now grouped as diffuse gliomas, depending on the growth pattern, biological behavior. Routine pathological evaluation of high-grade glioma samples should include mutational tests to determine the loss of function of the enzyme isocitrate dehydrogenase (IDH). Immunohistochemistry (IHC) for the IDH mutation is more common in gliomas, IDH1 R132H, captures approximately 90 percent of IDH mutations in gliomas. If the mutant IDH1 R132H is negative, the sequencing of IDH1 and IDH2 should be prioritized in all patients with grade III gliomas and in younger patients ( $<55$ years) with glioblastoma, since the distinction between IDH-mutant tumors and HDIWildtype has fundamental prognostic implications in predicting a better response to treatment [11].

In selected cases, $1 \mathrm{p} / 19 \mathrm{q}$ codeletion tests (tumors with oligodendroglial histopathological characteristics) should be requested. The methylation profile, to determine the methylation status of the 06-methylguanine-DNA methyltransferase (MGMT) promoter, is useful for prognosis and predicts the response to chemotherapy with alkylating agents. It is a powerful method to evaluate an aspect of the epigenetic landscape of brain tumors and is already part of the standard application to classify brain tumors [12].

\section{CASE 1}

The presentation of glioblastoma in cerebellum is extremely rare, corresponds to $0.24 \%$ to $1 \%$ of total glioblastomas and few reports of clinical cases with these characteristics have been published, hence the importance of our report, being the first in our country. Its pathogenesis and prognosis are not yet fully clarified due to such an infrequent presentation and therefore few reports, there are some data that suggest a worse prognosis. CNS neoplasms have different origins such as: neuroepithelial tissue, meninges, lymphatic and hematopoietic, germ cells, selar region, metastatic, cranial and paraspinal nerves [10]. There are few proven etiological factors for the development of these tumors: exposure to tobacco, the use of pesticides and products linked to the oil industry, as well as prior therapeutic exposure to ionizing radiation, in our first reported case the patient has the history having received maximum-dose holoencephalic radiotherapy, for which the appearance of a second tumor compatible with glioblastoma in the previously irradiated region was associated. On the other hand, and as corresponds to our second case presented, glioblastomas can also occur de novo, that is, without injury and / or previous radiation treatment [12].

GBMlocated in the posterior fossa can cause various cerebellar symptoms such as headache, gait disorders, ataxia, nausea and vomiting. These findings may suggest the existence of a massive lesion in the posterior fossa [13]. In the differential diagnosis of GBM located in the posterior fossa in adults, diseases such as metastases, abscesses, hemangioblastoma, cystic astrocytoma and entities such as encephalitis, tuberculomas or multiple sclerosis should be considered. The first differential diagnosis raised in case 1 discussed was that of medulloblastoma, mainly due to the patient's history and the very rare location of the patient. The standard diagnostic imaging method is brain MRI, where they appear as heterogeneous masses. Both performed as a diagnostic method in our patients. The images corresponding to metastases, abscesses and cerebellar infarction are similar with GBM, therefore, the differential diagnosis of this pathology is difficult, with metastases being the first approach to a mass in the posterior fossa [14]. Tumors with contrast hypercaptation and central hypodensity due to necrosis are characteristic of the posterior fossa GBM as well as the level of vascularization of the tumor that is an important characteristic in the differentiation of GBM and metastasis, the first being a classically very tumor vascularized [15].

The treatment for GBM of the posterior fossa is the same as supratentorial tumors, knowing that surgical resection is conditional on location. In our case, given the sudden presentation and poor general condition, since the patient had already received the maximum dose of radiotherapy, it was decided to start temozolomide $200 \mathrm{mg} / \mathrm{m} 2$ D1-D5 every 28 days by nasogastric tube and joint management with the $\backslash$ palliative care team. Patient dies after receiving the first cycle, 


\section{Cancer Therapy \& Oncology International Journal}

evolution consistent with the prognosis of these tumors, where the GBM located in the posterior fossa has been described with faster progression and worse prognosis compared to the supratentorial location [16].

\section{CASE 2}

Molecular markers such as isocitrate dehydrogenase - 1 (IDH1) or 06 methylguanine-DNA-methyl transferase (MGMT) they only have prognostic implication in supratentorial presentation glioblastomas [17]. There is not enough data regarding spinal cord glioblastoma, the diagnostic method of choice is magnetic resonance with a sensitivity close to $95 \%$ and a specificity of $85 \%$ for this type of tumors $[17,18]$, the data regarding At baseline behavior they are variable since cytoreduction has not been compared to biopsy, in both cases complementary treatment with radiotherapy and chemotherapy show excellent results for disease control; some clinical case reports reveal a discrete benefit in overall survival for patients with astrocytoma; surgical resection is not recommended because the interface of healthy tissue and infiltrative tissue cannot be differentiated by the tumor [16,19]; Adams et al. I report an increase in neurological impairment of patients undergoing surgery without an increase in survival. In terms of treatment, temozolomide associated with radiotherapy is the standard of care (SOC) for this type of tumors. Shirato et al. Survival report of up to 4.8 years reached radiotherapy dose of 6500 cGy. Marchan et al and Shirato et al; reported that such high doses should only be applied in patients with motor function compromised with tumor location at the dorsal or lumbar level, resulting in a radiocordectomy; Hernandez - Duran et al, found no statistically significant differences for patients who received radiotherapy associated with tamozolomide vs radiotherapy alone; which would explain a biological behavior different from that of cerebral Glioblastoma [20,21].

\section{Conclusion}

In general, the presentation of glioblastomas occurs in the supratentorial region but in less than $4 \%$ of cases occur in the posterior fossa particularly in the cerebellum, there are very few cases reported. Its pathogenesis and prognosis are not yet fully clarified, there are some data that suggest a worse prognosis. The differential diagnosis with metastatic posterior fossa tumors or cerebellar abscesses is a challenge for the doctor due to the similarity in the location, for this the magnetic resonance imaging (MRI) is mandatory as well as the pathological anatomy and the molecular diagnosis. The treatment for these lesions is like the supratentorial GBM, knowing that surgical resection is conditioned by its location and the implications in neurological sequelae, which is why it is very limited.

Spinal cord glioblastoma is an extremely rare, disease with a poor prognosis; this does not allow the realization of clinical studies that help to find new therapeutic strategies, the present review of the literature is limited due to the poor information available about this disease; Radical surgery could probably mean a slight increase in overall survival, however it is not widely recommended due to the possible neurological sequelae and neurological deterioration of patients, radiotherapy associated with chemotherapy remains the treatment of choice, and as a subsequent line of treatment we have antiangiogenic agents such as bevacizumab that represent an alternative especially in cerebral GBM. In the era of molecular biology; Brain glioblastoma information has given new alternatives for this type of tumor with drugs such as regorafenib thanks to the REGOMA study (GBM) that was superior to lomustine; however, it is necessary to design clinical studies that allow us to know the tumor biology of spinal cord glioblastomas and identify possible therapeutic targets.

Both reported cases correspond to the same pathological entity with two very rare presentation locations and with limited data in the literature. We believe that our report is important as a contribution, being the first in our country.

\section{References}

1. Walter J, Koch A, Herbold C, Schiffler S, Reichart R, et al. (2013) Multifocal Glioblastoma Multiforme in the Posterior Fossa Mimicking Cerebral Metastases: Case Presentation and Review of the Current Literature J Neurol Surg A 74(Suppl 1): e30-e35.

2. Perez CA, Thorstad WL (2013) Perez and Brady's Principles and Practice of Radiation Oncology. 6th ed. Philadelphia: Lippincott Williams and Wilkins, Wolters Kluwer Business, Netherlands, pp. 659694.

3. Koeller KK, Rosenblum RS, Morrison AL (2000) Neoplasms of the spinal cord and filum terminale: Radiologic-pathologic correlation. Radiographics 20: 1721-1749.

4. Jeong SM, Chung YG, Lee JB, Shin IY (2010) Intracranial dissemination from spinal cord anaplastic astrocytoma. J Korean Neurosurg Soc 47(1): 68-70.

5. Shen CX, Wu JF, Zhao W, Cai ZW, Cai RZ, et al. (2017) Primary spinal glioblastoma multiforme: A case report and review of the literature. Medicine (Baltimore) 96(16): e6634.

6. Morais N, Mascarenhas L, Soares-Fernandes JP, Silva A, Magalhães Z, et al. (2013) Primary spinal glioblastoma: A case report and review of the literature. Oncol Lett 5: 992-996.

7. Asano N, Kitamura K, Seo Y, Mukai K, Soga T, et al. (1990) Spinal cord glioblastoma multiforme with intracranial dissemination--case report. Neurol Med Chir (Tokyo) 30(7): 489-494.

8. Beyer S, von Bueren AO, Klautke G, Guckenberger M, Kortmann RD, et al. (2016) A Systematic Review on the Characteristics, Treatments and Outcomes of the Patients with Primary Spinal Glioblastomas or Gliosarcomas Reported in Literature until March 2015. PLoS One 11(2): e0148312.

9. Walker A, Robins M, Weinfeld F (1985) Epidemiology of braintumors: the national survey of intracranialneoplasms. Neurology 35(2): 219226.

10. Louis DN, Perry A, Reifenberger G, von Deimling A, Figarella-Branger D, et al. (2016) The 2016 World Health Organization Classification of tumors of the central nervous system: a summary. Acta Neuropathol 131(6): 803-820 


\section{Cancer Therapy \& Oncology International Journal}

11. Ohgaki H, Kleihues P (2013) The definition of primary and secondary glioblastoma. Clin Cancer Res 19(4): 764-772.

12. Capper D, Jones DTW, Sill M, Hovestadt V, Schrimpf D, et al. (2018) DNA methylation-based classification of central nervous system tumours. Nature 555(7697): 469-474.

13. George Chater Cure, Gerardo Aristizabal, Jorge Aristizabal, Carmen Lucia Roa (2011) Demographic and pathologic characteristics of the central nervoussystem tumors atended in clinica El Bosque - Bogotá. Acta Neurol Colomb 27(2)

14. Miller EM, Mani RL, Townsend JJ (1976) Cerebellar glioblastoma multiforme in an adult. Surg Neurol 5(6): 341-343.

15. Zito JL, Siva A, Smith TW, Leeds M, Davidson R (1983) Glioblastoma of the cerebellum. Computed tomographic and pathologic considerations. Surg Neurol 19(4): 373-378.

16. Jallo GI, Kothbauer KF, Epstein FJ (2001) Intrinsic spinal cord tumor resection. Neurosurgery 49(5): 1124-1128.

17. Johnson DR, O'Neill BP (2012) Glioblastoma survival in the United States before and during the temozolomide era. J Neurooncol 107(2): 359-364.
18. Konig SA, Roediger T, Spetzger U (2012) Treatment of recurrent primary spinal glioblastoma multiforme-case report. J Neurol Surg A Cent Eur Neurosurg 73(4): 256-261.

19. Constantini S, Miller DC, Allen JC, Lucy B Rorke, Diana Freed, et al. (2000) Radical excision of intramedullary spinal cord tumors: surgical morbidity and long- 44. term follow-up evaluation in 164 children and young adults. J Neurosurg 93: 183-193.

20. McLaughlin MP, Buatti JM, Marcus RB Jr, Maria BL, Mickle PJ, et al. (1998) Outcome after radiotherapy of primary spinal cord glial tumors. Radiat Oncol Investig 6(6): 276-280.

21. Shirato H, Kamada T, Hida K, Koyanagi I, Iwasaki Y, et al. (1995) The role of radiotherapy in the management of spinal cord glioma. Int J Radiat Oncol Biol Phys 33(2): 323-328.

\section{Your next submission with Juniper Publishers will reach you the below assets}

- Quality Editorial service

- Swift Peer Review

- Reprints availability

- E-prints Service

- Manuscript Podcast for convenient understanding

- Global attainment for your research

- Manuscript accessibility in different formats

( Pdf, E-pub, Full Text, Audio)

- Unceasing customer service

Track the below URL for one-step submission https://juniperpublishers.com/online-submission.php 